\title{
Household factors associated with managing the HIV positive population and meeting the UNAIDS goals
}

\author{
Gary Gaumer ${ }^{1}$, Ekwu B. Ochigbo ${ }^{1}$, Roya Sherafat-Kazemzadeh¹, Elad Daniels ${ }^{1}$, Jessica Brown ${ }^{1}$, Clare L. Hurley ${ }^{1}$, A. K. \\ Nandakumar ${ }^{1}$ \\ 1 The Institute for Global Health and Development, The Heller School for Social Policy and Management, Brandeis University, Waltham, \\ Massachusetts, USA \\ Keywords: viral load suppression, antiretroviral therapy, household factors, africa, hiv \\ https://doi.org/10.29392/001c.28068
}

\section{Journal of Global Health Reports}

Vol. 5, 2021

\begin{abstract}
Background
While poor countries have made progress attaining the The Joint United Nations Programme on HIV/AIDS (UNAIDS) goals for 2025, continued progress depends on continued accessibility of program services, as well as continued improvements in compliant behavior by HIV positive populations. This paper examines household survey data in four African countries pertaining to those critical behaviors and identifies the key population barriers for attaining UNAIDS goals.
\end{abstract}

\section{Methods}

This study used Population-based HIV Impact Assessment (PHIA) survey data for Zambia, Malawi, Eswatini, and Tanzania to examine household and other influences associated with effectively managing HIV-infected adults using three key outcomes: (i) self-awareness of HIV status, (ii) antiretroviral therapy adherence, and (iii) rate of viral load suppression (VLS).

\section{Results}

Factors found to increase HIV risk also posed barriers to awareness and viral suppression, such as being young, having multiple partners, and having a job outside the home. Additional barriers to awareness and viral suppression were low education, low wealth, low knowledge of HIV, and the HIV status and gender of the household head. The most consistent factor influencing awareness and viral load suppression was the gender of the individual. Women were much more likely to be aware of their HIV status and more likely to be virally suppressed at rates almost twice as high as comparable men. Our analysis shows that the gender differential for awareness seems primarily due the testing and other services provided for women giving birth. We also found that the VLS gender gap was not related birthing-related services.

\section{Conclusions}

The most substantial barrier to achieving UNAIDS goals appears to be poorer compliance by men regarding testing and sustained VLS. Routinely providing HIV testing and other HIV information during antenatal care (ANC) may have contributed to improved rates of HIV-status awareness of birthing-age women. New programs to routinely integrate HIV testing into men's health care in workplaces or other settings could improve men's awareness and compliance with treatment. Also needed are more effective interventions to target sectors of the population that are less likely to adhere to treatment regimens, such as persons with low-education levels, low wealth, and/or low knowledge of HIV.

This study examines Population-based HIV Impact Assessment (PHIA) household survey data in four sub-Saharan African (SSA) countries to understand the personal, household and community factors that are associated with awareness of human immunodeficiency virus (HIV) status and continued viral load suppression (VLS) among HIV-positive individuals. The Joint United Nations Programme on HIV/
AIDS (UNAIDS) 95-95-95 cascade goals for 2025 depend critically on both accessibility of program activities as well as compliant behavior of households. ${ }^{1}$ Specifically, current UNAIDS targets are the following:

1. $95 \%$ of HIV positive persons should be aware of their positive status. This requires testing and being told the test result. Without determining HIV positive sta- 
tus, enrolling in antiretroviral treatment (ART) (and the associated treatment as prevention [TasP]) cannot be initiated, nor can persons modify their risk behaviors accordingly. Being concerned about status will vary across individuals and over time. The decision to seek voluntary testing will depend on the level of concern, relevant barriers, and access to testing services.

2. $95 \%$ of those diagnosed with HIV infection will receive sustained ART program services. In addition to access to services, meeting this goal will require willingness to accept treatment as well as continued adherence to treatment.

3. $95 \%$ of those persons on ART treatment will have suppressed viral loads. The effectiveness of ART treatment is indicated by the extent of VLS. While VLS effectiveness can vary by person and by type of antiretroviral (ARV) drug, personal behavior is important in rigid adherence to the treatment plan (dose, timing of ARV drugs), as well as adhering to regular provider visits to assure that the treatment plan does not need to be changed to achieve and maintain VLS.

For each of these targets, good access to ART services is a requirement. Other key factors are household/individual decision-making and external factors that can often become barriers to deciding to be tested for HIV and starting and continuing on ART, such as social stigma pressures and gender norms.

To our knowledge this research on household factors that drive achievement of the UNAIDS goals is the first study of this topic using PHIA data.

\section{AWARENESS AND TESTING DEMAND}

The reluctance for individuals to seek voluntary HIV testing has been a longstanding obstacle and has been studied extensively in low- and middle-income countries, as well as in other populations. The frequently mentioned barriers to seeking testing are knowledge of HIV, being male, being young, the stigma associated with being HIV positive, and the inconvenience of testing services. ${ }^{2-5}$ To illustrate some of these barriers, a study of young adults in SSA found odds ratios of being tested about twice as high for older youth (odds ratio (OR) 2.19) and those with comprehensive knowledge of HIV (OR 1.98). ${ }^{2}$ Young men had much lower odds of HIV testing than young women (OR 0.32). A large qualitative study by Camlin et al. (2016) in eight locations in Kenya and Uganda demonstrated that lower testing rates for men were attributed to cultural and other barriers, including men's travel for work and gender norms "valorizing risktaking and discouraging health-seeking behavior." 6 The male reluctance to be tested was also attributed to poor access and inflexible operating hours of testing locations. To confirm the importance of convenience of options for testing locations, a systematic review of 126 studies of HIV testing modalities in facilities and community-based approaches (home, mobile, index, key populations, campaign, workplace, and self-testing) showed that expanding community sources can increase testing rates of the difficult to reach populations (men, young adults, and high-risk persons). ${ }^{4}$

\section{ART ADHERENCE AND VIRAL LOAD SUPPRESSION}

The medical literature had been fueling the refinement of the U.S. President's Emergency Plan for AIDS Relief (PEPFAR) strategy of continuing to scale up ART caseloads, making it a centerpiece of the overall prevention and program strategy. In an extensive review of the literature on TasP, Holmes et al., (2017) ${ }^{7}$ found there was compelling evidence that early intervention of ART for HIV positive individuals will prevent transmission of the disease. ${ }^{8-12}$ Studies with discordant couples leave little doubt that early ART treatment is effective from society's standpoint. ${ }^{9,13}$ Studies of ART treatment in poor countries ${ }^{14,15}$ confirmed that expansion of ART was not just good medicine, but it was cost effective from society's point of view. Providing pre-exposure prophylactic drugs (e.g. PrEP) to high-risk persons who are HIV negative is also demonstrated to be cost effective ${ }^{16}$ as a preventative measure.

The success of ART depends critically on the extent to which ART patients continue to adhere to the prescribed drug regimen forever. The "dropout" of HIV positive patients from treatment has three negative health effects: (1) these patients get sicker and die sooner than if they had continued treatment, (2) while on treatment, the vast majority of ART patients cannot transmit their HIV (the drugs lower their viral load) and dropping out of treatment negates this important benefit, and (3) the stopping and starting of treatment can also lead to build up of drug resistance. Thus, retaining ART patients is critical for impacting both health outcomes and buildup of the program's efficiency. In an early systematic review of 32 studies with patients from 13 countries going on ART from 2000-2007 showed the average patient retention rate at 12 months to be $75 \% .{ }^{17}$ Two subsequent systematic reviews ${ }^{18,19}$ showed 12-month retention rates of 77.4 and 80.1 respectively. A more recent report from WHO, including 23 countries, showed the average retention for ART patients went from $86 \%$ at 12 months to $72 \%$ at 60 months. ${ }^{20}$ But little is known about the household and community factors that drive ART retention rates among patients.

Recent studies describe patterns of association between ART retention and patient characteristics. In central Kenya about 24,000 patients from 2004-2012 who were over age 20 were followed for 36 months. The 12-month loss to follow up (LTFU) was $14.7 \% .^{21}$ Authors report that being an older male, on a tenofovir disoproxil fumarate (TDF)-based regimen, with stage 3 or 4 illness, or being single or divorced were associated with LTFU at 12 months. An earlier Ethiopian study using ART patients from 2005-2013 used a definition of LTFU of three months without treatment, death, or otherwise terminated from the program. ${ }^{22}$ Risk factors associated with LTFU in that study were "low CD4 counts, adolescence, being in good health, regimen substitution, or advanced clinical stage.” A Nigerian cohort of 245,000 ART patients from 2004-2017 demonstrated that factors associated with LTFU include being male, use of second line regimen drugs, increasing age, unsuppressed viral load or targeted viral load test indication, residence in the north, especially North Central region, increasing duration of ARV refills, or ART initiation of less than 6 months. ${ }^{23}$

A number of factors related to ART compliance and re- 
tention have been studied in SSA. One study at primary care sites in South Africa reports a pattern of retention related to psychosocial support. ${ }^{24}$ Other research found predictors of LTFU to be younger age, male, low baseline CD4, stage 3 or 4 illness, low baseline body mass index (BMI), more than $10 \%$ weight loss, or decision to seek care from higherlevel facilities. ${ }^{24-31}$ These studies have demonstrated that aging seems a critical issue for adherence behavior. In a meta-analysis by Ghidei (2013), ${ }^{32}$ persons over age 50 had $27 \%$ lower risk for non-adherent behaviors than younger adults. And a study of SSA 33,34 showed that older adults (age 35-49) were more likely to remain virally suppressed than younger adults after a peer training program.

Recently, Tomita et al. (2019) ${ }^{35}$ studied the prevalence of unsuppressed VL in a hotspot situation in South Africa in 2011-2014. Young women, number of sexual partners, transiency, and longer residence in HIV-hotspot communities are important determinants of unsuppressed VL in a hyperendemic rural African setting.

Wealth effects on adherence to the prescribed regimen of ART have also been studied. Peltzer and Pengpid (2013) 36 conducted a review of 62 studies of socioeconomic status measures and adherence in low- and middle-income countries and found inconsistent impacts of wealth and other economic measures on adherence. Some studies found economic status measures to be positive drivers of adherence; other studies found insignificant or even negative influences on adherence. A review of adherence studies in India by Sahay et al. $(2011)^{37}$ echoes the inconsistency of economic drivers of adherence.

\section{METHODS}

Our research objective was to examine indicators of adult behavior that are key to meeting UNAIDS goals for ending the HIV epidemic. We examined three key behavioral variables, all based on biometric laboratory analysis of blood samples taken from all willing respondents as part of the PHIA survey. The measures included:

1. Extent of awareness of HIV positive status for all persons testing positive for HIV: an explicit UNAIDS goal exists for $95 \%$ in 2025. In the four countries in this study, the PHIA average awareness rate was calculated to be $68.2 \%$ the year of the survey (Table 1).

2. Whether viral load was suppressed for all persons testing positive for HIV: an explicit UNAIDS goal exists of $86 \%$ in 2025 (.95x.95x.95). In the four study countries, the PHIA average HIV viral suppression rate was calculated to be $59.1 \%$ (Table 1 ).

3. Whether viral load was suppressed for all persons who started on ART less than 24 months prior to the survey (VLS24): this is not an explicit objective in meeting UNAIDS goals, but it provides a focus on new ART patients and the factors that are associated with early dropout behaviors. Table 1 shows the pooled mean of this measure to be $98.5 \%$.

The four study countries, Zambia, Malawi, Tanzania, and Eswatini, were quite different culturally, and subject to different epidemic influences. We tested hypotheses about drivers of the individual behaviors both within each of the countries and in a pooled framework. In the pooled statistical models, country dummy variables were included (Malawi=1.0) with the results reported in Tables S1 and S2 in the Online Supplementary Document.

While there will always be some geographical differences in behaviors due to cultural differences, there will also be person-to-person variations in behaviors and compliance to medical instructions. We also expect variations in behaviors regarding factors that are known to influence patients' choices will be more systematic. Some of these expected patterns include:

- Convenience - travel times to get care or drugs might be expected to systematically discourage access for persons living remotely.

- Household wealth quintiles - persons living in households that are wealthier may prefer to spend more on compliance behaviors and may be able to afford better transport and avoid convenience issues. Or such households may be able to avoid inconvenience by using a private (paid for out-of-pocket) clinic nearby.

- Knowledge and education levels - more education and/or knowledge of HIV would be expected to influence personal decision making about compliance or consulting with a medical professional, and we expect knowledge and education would improve awareness (and earlier testing) and more medically compliant behaviors.

- Household HIV treatment experience - individuals might be expected to be influenced in their behavior by household dynamics. For example, another person in the household with HIV or on ART might influence status awareness and/or treatment behaviors. More experience with HIV in the household would improve knowledge and tend to improve awareness and compliance behaviors. We include covariates in models for the number of persons in the household and both the HIV status and gender of the household head.

- Gender and age - typically women tend to show more concern about personal health than men 6 and we would expect to see this reflected in both awareness and compliance behaviors. We would hypothesize older persons to behave differently since, if no other reason, they have lived longer and have seen more effects of the disease during the long HIV epidemic. The literature also confirms medically compliant behavior increases with age. ${ }^{32-34,38-41}$

- Perceived external barriers to being tested or adhering to treatment - we would hypothesize that the more social stigma recognized by the respondent would discourage testing and/or adherence to ART treatment.

- Sexual practices and work outside the home - The models also include individual behavior, including number of sexual partners in the last 12 months, and whether the person worked outside the home in the last 12 months.

Following findings in other studies, ${ }^{21-23}$ our models also include the specific ARV drug that was detected in the biomarker blood examination and a variable for how many years it had been since the person first tested positive for 
Table 1. Descriptive data on HIV positive adults: awareness of positivity, viral load suppression, and viral load suppression of persons initiating ART $<24$ months prior to the PHIA survey

\begin{tabular}{|c|c|c|c|c|}
\hline Demographic, economic and household Variables & Group characteristics & $\begin{array}{r}\% \\
\text { Aware }\end{array}$ & $\begin{array}{r}\% \\
\text { VLS }\end{array}$ & $\%$ VLS ART 24 \\
\hline Total & & 68.2 & 59.1 & 89.5 \\
\hline \multirow{3}{*}{ Age } & $15-24$ years & 49.9 & 40.7 & 83.9 \\
\hline & $25-49$ years & 69.8 & 59.5 & 89.8 \\
\hline & $50+$ years & 72.8 & 69.3 & 91.5 \\
\hline \multirow{2}{*}{ Sex } & Male & 66.0 & 52.4 & 84.8 \\
\hline & Female & 71.5 & 62.9 & 91.9 \\
\hline \multirow{2}{*}{ Location } & Rural & 67.6 & 59.7 & 89.8 \\
\hline & Urban & 68.8 & 58.7 & 89.1 \\
\hline \multirow{3}{*}{ Education } & Less than primary & 73.6 & 64.6 & 88.9 \\
\hline & Secondary & 62.3 & 61.6 & 89.0 \\
\hline & Tertiary & 75.7 & 68.2 & 91.2 \\
\hline \multirow{2}{*}{ Employed } & Yes & 64.0 & 54.1 & 90.0 \\
\hline & No & 71.2 & 62.8 & 88.7 \\
\hline \multirow{3}{*}{ Wealth by quintile } & Q1 & 62.4 & 52.3 & 89.4 \\
\hline & Q2-4 & 68.1 & 59.2 & 89.3 \\
\hline & Q5 & 72.0 & 63.2 & 89.7 \\
\hline \multirow{3}{*}{ Household size } & $<4$ persons & 66.5 & 57.4 & 91.1 \\
\hline & 4-9 persons & 69.7 & 60.7 & 88.7 \\
\hline & $10+$ persons & 62.7 & 54.0 & 88.2 \\
\hline \multirow{2}{*}{ Female head of household } & Yes & 71.7 & 62.8 & 88.9 \\
\hline & No & 66.0 & 56.9 & 89.8 \\
\hline \multirow{2}{*}{ Head of household is HIV positive } & Yes & 70.8 & 61.8 & 90.7 \\
\hline & No & 58.3 & 48.8 & 83.4 \\
\hline \multirow{4}{*}{ Duration HIV positive } & $<3$ years & -- & 66.6 & 86.3 \\
\hline & 4-6 years & -- & 79.1 & 89.4 \\
\hline & $5-9$ years & -- & 84.4 & 94.0 \\
\hline & $10+$ years & -- & 81.6 & 87.3 \\
\hline \multirow{2}{*}{ Seen medical doctor in last 12 months } & Yes & 82.0 & 71.8 & 89.2 \\
\hline & No & 47.1 & 44.3 & 88.0 \\
\hline \multirow{3}{*}{ Travel time to medical doctor } & $<1$ hour & 48.1 & 85.6 & 88.0 \\
\hline & 1-2 hour & 33.1 & 86.5 & 89.5 \\
\hline & $>2$ hour & 18.8 & 83.5 & 90.8 \\
\hline \multirow{3}{*}{ Number of sex partners in last 12 months } & 0 & 73.2 & 64.2 & 92.4 \\
\hline & 1 & 70.0 & 60.5 & 89.3 \\
\hline & $2+$ & 59.0 & 46.7 & 87.2 \\
\hline \multirow{3}{*}{ ARV medication } & Efavirenz & 97.6 & 92.7 & 92.7 \\
\hline & Lopinavir & 94.8 & 90.5 & 100 \\
\hline & Nevirapine & 98.5 & 83.4 & 93.3 \\
\hline \multirow{4}{*}{ Country } & Malawi & 76.9 & 68.3 & 89.7 \\
\hline & Eswatini & 87.0 & 73.1 & 90.2 \\
\hline & Zambia & 66.6 & 59.2 & 88.5 \\
\hline & Tanzania & 68.2 & 59.1 & 89.5 \\
\hline
\end{tabular}

Notes: VLS denotes viral load suppression; HIV+ denotes human immunodeficiency virus positive; ART denotes antiretroviral therapy; VLS ART 24 denotes whether viral load was suppressed for all persons who started on ART less than 24 months prior to the survey; Aware denotes awareness of HIV status; table values are population weighted for four country pooled sample. 
HIV.

This study used publicly available PHIA household survey data for one year (2015 or 2016) from Zambia, Malawi, Tanzania, and Eswatini. ${ }^{42}$ These surveys are similar in content and operation to the Demographic and Health Surveys (DHS) but are adapted to be used to study HIV/AIDS risk behaviors and other research questions pertaining to HIV/ AIDS. The PHIA data consist of a complex survey process with a stratified, multistage probability sample design with different weighting systems designed for various types of analysis. Because the key measures here are derived from the biomarker process, the weighting approach utilized is the blood test base weights. The jackknife repeated replication (JRR) method was also employed for the variance estimation.

\section{RESULTS}

Basic descriptive data on percent population HIV positive and key study variables are shown in Figure 1 and Table 1. Figure 1 aggregates data across the four PHIA countries by nine age groups (indicated by their midpoints, except for the last group which includes all persons ages 50 or older). Awareness and VLS in the HIV-positive population both increase with age. In addition, persons never on ART peaks at $11.7 \%$ for those in their early 20 s and declines in both younger and older age groups.

\section{AWARENESS OF HIV POSITIVITY}

Attainment of the UNAIDS goals for ending the epidemic depends critically on getting infected persons on sustained ART therapy to keep them virally suppressed so they cannot infect others. This can only be accomplished if infected persons are tested and told they are HIV positive. Becoming aware of positivity is the necessary first step in closing down the epidemic. PHIA not only asks respondents what their HIV status is, but determines through biomarker lab work if they are indeed positive or not and makes a determination if each respondent who is truly HIV positive was aware of it. Across the pooled sample of four countries, awareness of adults ages 15 and higher averages a bit more than two-thirds of the HIV positive population (Table 1 reports $68.2 \%$ are aware). There are substantial differences across countries in awareness rates, ranging from $66.6 \%$ in Zambia to $87 \%$ in Eswatini. Table 1 also shows that levels of HIV positive awareness are higher for women, people who are older, those who have seen a medical doctor in last 12 months, not employed, those with fewer sex partners, wealthier persons, and those who have an HIV-positive household head.

Weighted logistic regression models were estimated on awareness (or not) for all HIV-positive persons in the PHIA samples, see Table 2 . We report the log odds ratio, the $95 \%$ confidence interval, and the $P$ value for the regression coefficient. The finding for the variable for sex (male, female) is very striking. Under the pooled column model, the coefficient for men is the first row. The estimated odds ratio coefficient (0.554) indicates that relative to women (females

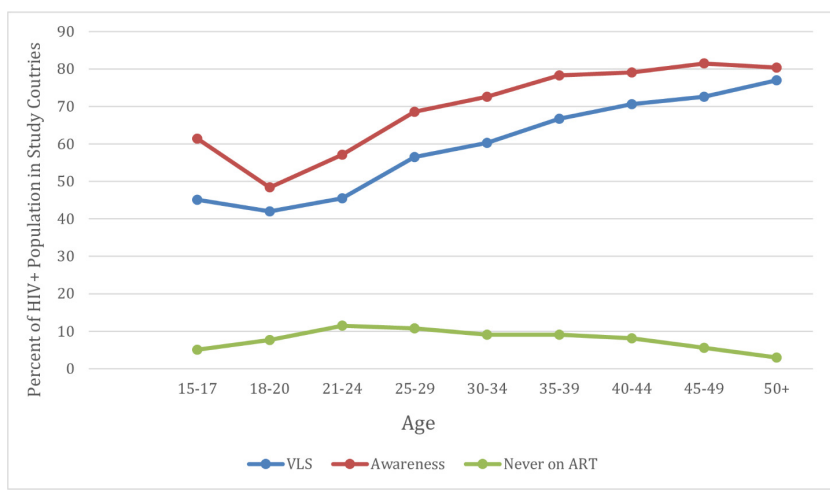

Figure 1. PHIA survey data on HIV/AIDS outcomes for the HIV positive population.

Notes: VLS denotes viral load suppression; HIV+ denotes human immunodeficiency virus positive; ART denotes antiretroviral therapy.

$=1$ ), men are $55 \%$ as aware of their HIV status as women (holding all other factors constant). The $95 \%$ confidence interval for the men's odds ratio is 0.43 to 0.71 .

Consistent patterns of lower awareness are seen for men, young adults $15-24$, persons in the poorest quintile of households, and those in households headed by persons who are not HIV positive. Men have awareness levels that are $45 \%$ lower than comparable women. Young adults ages 15-24 have awareness levels far lower than older population groups, other things the same. We find no difference in awareness between persons with no partners and those with only one partner. But awareness is $28 \%$ lower for persons who have multiple sex partners (relative to having no sex partners), though not consistently across the country models.

Persons who are HIV positive who live in a household where the head of the household is male are likely to be slightly more aware of their HIV status, while persons living in a household where the head is known to have HIV are 2.7 times more likely to be aware of their status. This indicator is highly significant in both the pooled sample and all individual countries.

Household wealth levels show no differences in awareness between persons in the low- and medium-wealth levels. However, high wealth is associated with $78 \%$ higher awareness than poor persons in the pooled sample.

No apparent pattern is evident for awareness and educational attainment or household size, though there is weak evidence that secondary education may harm awareness and very large families ( $>10)$ may improve it. Eswatini shows stronger patterns, suggesting that higher education harms awareness and larger families improve it.

A high level of HIV knowledge is associated with more awareness; HIV positive persons with high knowledge are about $35 \%$ more likely to be aware, other things the same, and this trend is even higher in Zambia and Tanzania. Working outside the home in the last 12 months is generally unrelated to awareness rates. Persons believing that having HIV infection is subject to social stigma is not associated with awareness. 
Table 2. Model results for awareness odds ratios and confidence intervals by sample

\begin{tabular}{|c|c|c|c|c|c|}
\hline Awareness model variables & Pooled & Zambia & Malawi & Tanzania & Eswatini \\
\hline \multirow[t]{2}{*}{ Gender: Male (Fem=1.0) } & $0.554^{* * *}$ & $0.478^{* * *}$ & 0.643 & $0.487^{* * *}$ & $0.362^{* * *}$ \\
\hline & $(0.432-0.711)$ & $(0.293-0.782)$ & $(0.404-1.023)$ & $(0.327-0.725)$ & $(0.265-0.495)$ \\
\hline \multirow[t]{2}{*}{ HIV + age: 25 to 49 years (age $15-24=1$ ) } & $2.941^{* * *}$ & $2.552^{* * *}$ & $3.508^{* * *}$ & $1.672^{* *}$ & $4.010^{* * *}$ \\
\hline & $(2.252-3.842)$ & $(1.377-4.730)$ & $(1.811-6.795)$ & $(1.005-2.783)$ & $(2.797-5.748)$ \\
\hline \multirow[t]{2}{*}{$50+$ years (age $15-24=1$ ) } & $3.981^{* * *}$ & $4.981^{* * *}$ & $3.294^{* * *}$ & $1.853^{*}$ & $6.356^{* * *}$ \\
\hline & $(2.640-6.003)$ & $(2.174-11.41)$ & $(1.436-7.553)$ & $(0.994-3.455)$ & $(3.597-11.23)$ \\
\hline \multirow[t]{2}{*}{ \# Partners 12 months: One (none=1.0) } & 0.998 & 1.179 & 0.797 & 0.873 & 0.942 \\
\hline & $(0.775-1.286)$ & $(0.758-1.834)$ & $(0.498-1.277)$ & $(0.633-1.203)$ & $(0.629-1.411)$ \\
\hline \multirow[t]{2}{*}{ Multiple (none=1.0) } & $0.716^{* *}$ & 0.960 & 0.495 & 0.812 & 0.641 \\
\hline & $(0.521-0.984)$ & $(0.538-1.713)$ & $(0.235-1.044)$ & $(0.515-1.280)$ & $(0.384-1.071)$ \\
\hline \multirow[t]{2}{*}{ Education: Secondary $(<S=1.0)$} & 0.813 & 0.833 & 0.803 & 1.203 & 0.780 \\
\hline & $(0.637-1.037)$ & $(0.564-1.230)$ & $(0.490-1.314)$ & $(0.815-1.776)$ & $(0.557-1.094)$ \\
\hline \multirow[t]{2}{*}{ Tertiary $(<S=1.0)$} & 0.738 & 0.655 & 0.771 & 0.989 & $0.629^{* *}$ \\
\hline & $(0.501-1.088)$ & $(0.324-1.323)$ & $(0.217-2.747)$ & $(0.558-1.750)$ & $(0.430-0.920)$ \\
\hline \multirow[t]{2}{*}{ Wealth: Q 2-4 (W1=1.0) } & 1.235 & 1.337 & 1.285 & 1.487 & 0.822 \\
\hline & $(0.914-1.668)$ & $(0.717-2.492)$ & $(0.688-2.400)$ & $(0.916-2.415)$ & $(0.576-1.174)$ \\
\hline \multirow[t]{2}{*}{ Q5 (W1=1.0) } & $1.779^{* * *}$ & $2.808^{* * *}$ & 1.282 & 1.495 & 0.941 \\
\hline & $(1.261-2.509)$ & $(1.320-5.972)$ & $(0.667-2.467)$ & $(0.765-2.922)$ & $(0.546-1.621)$ \\
\hline \multirow[t]{2}{*}{ Household size: 4 to $9(1-3=1.0)$} & 1.085 & 1.408 & 0.796 & $1.381^{* *}$ & $1.435^{* *}$ \\
\hline & $(0.872-1.352)$ & $(0.934-2.124)$ & $(0.513-1.235)$ & $(1.021-1.868)$ & $(1.068-1.929)$ \\
\hline \multirow[t]{2}{*}{10 and over $(1-3=1.0)$} & 1.431 & 1.758 & 1.231 & 0.857 & $2.079^{* *}$ \\
\hline & $(0.931-2.201)$ & $(0.821-3.764)$ & $(0.394-3.844)$ & $(0.466-1.574)$ & $(1.156-3.738)$ \\
\hline \multirow[t]{2}{*}{ Household head: HIV+ (HHH HIV neg =1.0) } & $2.681^{* * *}$ & $3.511^{* * *}$ & $2.162^{* *}$ & 1.463 & $1.463^{* *}$ \\
\hline & $(2.019-3.561)$ & $(2.134-5.776)$ & $(1.213-3.854)$ & $(0.971-2.204)$ & $(1.020-2.098)$ \\
\hline \multirow[t]{2}{*}{ Household head: Male (HHH fem=1.0) } & 1.259 & 1.418 & 1.113 & 1.261 & 0.861 \\
\hline & $(0.960-1.650)$ & $(0.881-2.282)$ & $(0.661-1.875)$ & $(0.870-1.829)$ & $(0.629-1.180)$ \\
\hline \multirow[t]{2}{*}{ Work outside home Last 12 months (not=1.0) } & PHIA 0.871 & 0.830 & 0.875 & $0.658^{* *}$ & 0.947 \\
\hline & $(0.705-1.077)$ & $(0.568-1.211)$ & $(0.556-1.375)$ & $(0.474-0.913)$ & $(0.716-1.253)$ \\
\hline HIV knowledge (low =1.0) & $1.347^{* *}$ & 1.503 & 1.040 & $1.955^{* * *}$ & $\mathrm{na}$ \\
\hline
\end{tabular}




\begin{tabular}{|c|c|c|c|c|c|}
\hline & $(1.062$ - 1.707) & $(0.981-2.303)$ & $(0.532-2.033)$ & $(1.389-2.752)$ & \\
\hline \multirow[t]{2}{*}{ Stigma (Unlikely=1.0) } & 1.037 & 0.921 & 1.184 & na & na \\
\hline & $(0.924-1.165)$ & $(0.753-1.127)$ & $(0.957-1.466)$ & & \\
\hline \multirow[t]{2}{*}{ Constant } & $0.365^{* * *}$ & $0.155^{* * *}$ & 0.610 & $0.409^{* *}$ & $3.215^{* * *}$ \\
\hline & $(0.221-0.603)$ & $(0.0587-0.409)$ & $(0.186-2.001)$ & $(0.183-0.913)$ & $(1.664-6.212)$ \\
\hline Observations & 8,539 & 2,978 & 3,397 & 2,966 & 3,487 \\
\hline
\end{tabular}

Notes: * $P<0.05$, "*** $P<0.01$, ****** $P<0.001$. HIV denotes human immunodeficiency virus; HHH denotes head of household; $\mathrm{Q}$ denotes quintile; $\mathrm{W}$ denotes wealth; na denotes no data available for PHIA on HIV knowledge (Eswatini) or stigma (Tanzania, Eswatini). 
Table S1 in the Online Supplementary Document shows descriptive data collected from PHIA surveys of the reasons why untested people report they had never been tested for HIV. Aside from those who gave non-distinct answers of "other" or "don't know," the primary reason is that they didn't think they needed a test. Another common answer is they didn't want to know that they have HIV. Both answers were consistent for HIV-positive people who did not know their status when they completed the survey. Not knowing where to get tested was also a frequent response.

\section{VIRAL LOAD SUPPRESSION (VLS) AMONG THE HIV- POSITIVE POPULATION}

As shown in the descriptive information in Table 1 , only $59.1 \%$ of HIV-positive persons in the four study countries are suppressed based on the nearly 12,000 HIV-positive persons sampled by PHIA between 2015 and 2017. Table 1 also shows that viral load suppression is much higher in Eswatini (73.1\%) and Malawi (68.3\%). Further, that data shows higher viral suppression for persons who are female, older, unemployed, wealthier, have fewer sex partners, have an HIV-positive household head, have a female head of household, have seen a medical doctor recently, and have detectible Lopinavir in their blood.

The results of logistic regression models for VLS status among all HIV-positive persons are shown in Table 3 . These models show clear patterns for viral suppression for gender (males $48 \%$ less likely than females), low education (81\% more likely if they had a secondary education) and working outside of the home (39\% less likely).

\section{VLS AMONG THE HIV-POSITIVE PERSONS STARTING ART IN THE LAST 24 MONTHS}

The third outcome measure relates to persons who initiated ART in the last 24 months prior to completing the PHIA survey. We measured their adherence to ART by measuring the percent who were, at the time of the survey, viral-load suppressed. This is an indicator of adherence for relatively new ART patients. Table 1 describes the pattern of VLS of those recently initiating ART and shows the average VLS for these persons across the four study countries to be $89.5 \%$, with almost no difference across countries. The regression models are shown in Table 4. The sample of this subset of the HIVpositive population is small ( 275 across the three countries in the pooled sample).

Only three risk factors are significant for the VLS24 variable for these relatively new ART patients: being male (about $78 \%$ less likely to be suppressed), having a household head that is HIV positive (making suppression $330 \%$ more likely), and having multiple partners (about 1000\% more likely).

Gender is the most important barrier to improving VLS rates for patients who had started ART therapy in the last 24 months prior to the survey. After adjustment for other factors, VLS for these recently initiated ART patients is much higher for women (male patients have a 78\% lower odds of being virally suppressed than women, other things the same). More positive influences on staying suppressed are living in households where the head is also HIV positive and for persons having multiple sex partners.

The PHIA survey asked respondents to identify reasons why they were not on ARVs. Table S2 in the Online Supplementary Document shows these data for all aware persons who were not on ARVs at the time of the survey. For young persons, the cost of transport to get medications is the largest barrier. Men responded that they either felt too healthy for medication or the medication they had tried resulted in adverse side effects. For persons over 50 years of age poor experience with ARV side effects is a very important deterrent to staying on treatment.

\section{ANALYSIS OF THE GENDER DIFFERENCES}

Gender differences are the only common factor associated with non-compliant behavior across the three dependent variables. Being male is a substantial and consistent barrier for achieving more positive awareness, VLS and VLS24 behaviors. Is this the consequence of careless or 'valorizing' health behaviors by men ${ }^{6}$ or something else?

One important difference between men and women which might influence awareness and VLS are the prevention programs implemented by PEPFAR and other donors aimed at preventing mother-to-child transmission (PMTCT). These programs generally include mandatory HIV testing coupled with other informational services for pregnant women. ${ }^{43}$ This widespread program activity may be 'creating' the apparent gender gap for awareness and/or VLS by including testing, counseling, and even preemptive ARV treatment as part of antenatal and institutional birthing services for pregnant women. A study of the community impact of a new PMTCT program in a high prevalence area in South Africa shows that widespread PMTCT programs may explain the gender gap we see in HIV awareness and viral suppression. The program experienced a new client HIV-positive awareness rate increase from $14.3 \%$ to $45 \%$ over a six-year period, while the PMTCT rate fell from $6.9 \%$ to less than $1 \%$. Those living with HIV also showed a huge increase in ART usage from $10 \%$ to $88 \%$ over the period. ${ }^{44}$

Using the PHIA survey data, Table 5 shows weighted means for the three key variables for men, for women who have given birth, and for women who have not given birth. For variables Aware and VLS, it is clear that women who have not had a birthing experience are more similar to men than to women who have given birth. This certainly suggests an important aspect of the birthing experience that contributes to the gender differences for awareness and VLS in the HIV positive population. 
Table 3. Model results for viral load suppression for HIV+ persons: odds ratios and confidence intervals by sample

\begin{tabular}{|c|c|c|c|c|c|}
\hline Viral load suppression model variables & Pooled & Zambia & Malawi & Tanzania & Eswatini \\
\hline Gender: Male (Fem=1.0) & $0.523^{* *}$ & $0.460^{* *}$ & 0.560 & $0.432^{* *}$ & 0.696 \\
\hline & $(0.319-0.856)$ & $(0.228-0.929)$ & $(0.273-1.151)$ & $(0.226-0.825)$ & $(0.371-1.306)$ \\
\hline HIV+ Age: 25 to 49 years (Age $15-24=1$ ) & 1.896 & 2.764 & 2.171 & 0.813 & 1.822 \\
\hline & $(0.707-5.085)$ & $(0.882-8.661)$ & $(0.724-6.512)$ & $(0.319-2.068)$ & $(0.830-3.998)$ \\
\hline $50+$ years (Age 15-24=1) & 3.204 & $10.94^{* * *}$ & 1.913 & 2.400 & $4.432^{* * *}$ \\
\hline & $(0.835-12.30)$ & $(2.354-50.86)$ & $(0.534-6.860)$ & $(0.848-6.789)$ & $(1.595-12.32)$ \\
\hline \# Partners 12 months: One (None=1) & 0.951 & 0.988 & 1.158 & 0.871 & 1.301 \\
\hline & $(0.526-1.720)$ & $(0.514-1.899)$ & $(0.581-2.308)$ & $(0.551-1.378)$ & $(0.794-2.133)$ \\
\hline Multiple (None=1) & 1.202 & 1.403 & $4.342^{* *}$ & 0.750 & 1.269 \\
\hline & $(0.513-2.813)$ & $(0.474-4.155)$ & $(1.057-17.84)$ & $(0.434-1.299)$ & $(0.503-3.199)$ \\
\hline Education: Secondary $(<S=1.0)$ & $1.811^{* *}$ & 1.373 & 2.223 & 0.985 & 1.112 \\
\hline & $(1.057-3.102)$ & $(0.736-2.561)$ & $(0.861-5.740)$ & $(0.583-1.665)$ & $(0.670-1.846)$ \\
\hline Tertiary $(<S=1.0)$ & 2.084 & 1.649 & 2.561 & 1.465 & 1.586 \\
\hline & $(0.209-20.75)$ & $(0.224-12.13)$ & $(0.666-9.855)$ & $(0.653-3.285)$ & $(0.798-3.154)$ \\
\hline Wealth: Q2-Q4 (W1=1.0) & 0.907 & 1.104 & 0.477 & 1.127 & 0.862 \\
\hline & $(0.674-1.222)$ & $(0.468-2.604)$ & $(0.174-1.310)$ & $(0.542-2.342$ & $(0.494-1.504)$ \\
\hline $\mathrm{Q} 5(\mathrm{~W} 1=1.0)$ & $1.455^{* *}$ & 1.217 & 0.544 & 1.142 & 0.761 \\
\hline & $(0.987-2.145)$ & $(0.479-3.094)$ & $(0.173-1.716)$ & $(0.443-2.940)$ & $(0.328-1.769)$ \\
\hline Travel time to care- 1 to 2 hrs $(<1$ hour $=1.0)$ & 0.890 & 0.831 & 1.237 & na & 0.922 \\
\hline & $(0.507-1.560)$ & $(0.367-1.883)$ & $(0.662-2.312)$ & & $(0.553-1.536)$ \\
\hline Over 2 hours $(<1$ hour $=1.0)$ & 0.992 & 0.793 & 1.164 & na & 0.768 \\
\hline & $(0.618-1.594)$ & $(0.390-1.612)$ & $(0.517-2.623)$ & & $(0.352-1.677)$ \\
\hline Household size: 4 to $9(1-3=1.0)$ & 1.250 & 0.730 & 0.704 & $1.732^{* *}$ & $0.563^{* *}$ \\
\hline & $(0.791-1.974)$ & $(0.368-1.449)$ & $(0.370-1.341)$ & $(1.071-2.802)$ & $(0.328-0.966)$ \\
\hline 10 and Over $(1-3=1.0)$ & 0.725 & 0.891 & 0.633 & 1.616 & 0.882 \\
\hline & $(0.313-1.679)$ & $(0.335-2.376)$ & $(0.167-2.392)$ & $(0.560-4.669)$ & $(0.375-2.075)$ \\
\hline Household head: HIV + (HHH Neg =1.0) & 1.233 & 1.623 & $2.302^{* *}$ & 1.720 & 1.576 \\
\hline & $(0.525-2.894)$ & $(0.719-3.665)$ & $(1.050-5.050)$ & $(0.919-3.221)$ & $(0.935-2.653)$ \\
\hline
\end{tabular}




\begin{tabular}{|c|c|c|c|c|c|}
\hline Household head: Male (HHH Fem=1.0) & 0.940 & 1.313 & 0.941 & 1.384 & 1.136 \\
\hline & $(0.589-1.500)$ & $(0.652-2.642)$ & $(0.454-1.949)$ & $(0.748-2.562)$ & $(0.634-2.037)$ \\
\hline Employed past 12 months (Not employed =1) & $0.611^{* *}$ & 0.567 & 0.534 & 1.087 & 1.353 \\
\hline & $(0.409-0.913)$ & $(0.319-1.008)$ & $(0.277-1.030)$ & $(0.698-1.691)$ & $(0.833-2.196)$ \\
\hline Drug regimen- Efavirenz (Nevirapine or other=1.0) & 1.419 & $2.760^{* *}$ & na & na & 1.611 \\
\hline & $(0.489-4.122)$ & $(1.078-7.066)$ & & & $(0.959-2.705)$ \\
\hline Lopinavir (Nevirapine or other=1.0) & 2.655 & 2.624 & na & na & 1.194 \\
\hline & $(0.785-8.976)$ & $(0.638-10.80)$ & & & $(0.386-3.694)$ \\
\hline Duration of HIV +2 to 3 yrs $(<2$ years $=1.0)$ & 1.811 & 1.627 & 2.756 & 1.750 & 1.625 \\
\hline & $(0.336-9.767)$ & $(0.561-4.723)$ & $(0.531-14.31)$ & $(0.999-3.063)$ & $(0.680-3.884)$ \\
\hline 4 to 10 yrs $(<2$ years $=1.0)$ & 2.018 & 1.575 & $4.938^{* *}$ & $1.948^{* *}$ & 1.502 \\
\hline & $(0.355-11.48)$ & $(0.571-4.347)$ & $(1.091-22.34)$ & $(1.133-3.347)$ & $(0.651-3.465)$ \\
\hline Over 10 yrs $(<2$ years $=1.0)$ & 1.428 & 1.141 & 3.135 & 1.091 & 1.273 \\
\hline & $(0.216-9.423)$ & $(0.341-3.814)$ & $(0.586-16.77)$ & $(0.458-2.595)$ & $(0.486-3.336)$ \\
\hline HIV knowledge (Low =1.0) & 0.939 & na & 0.770 & 1.442 & na \\
\hline & $(0.521-1.694)$ & & $(0.320-1.854)$ & $(0.875-2.379)$ & \\
\hline Stigma (unlikely=1.0) & 0.985 & na & 0.867 & na & na \\
\hline & $(0.752-1.290)$ & & $(0.623-1.209)$ & & \\
\hline Constant & 9.557 & 1.018 & 1.985 & 0.987 & 3.668 \\
\hline & $(0.380-240.1)$ & $(0.102-10.16)$ & $(0.173-22.73)$ & $(0.217-4.478)$ & $(0.986-13.64)$ \\
\hline Observations & 7,758 & 3,031 & 3,066 & 2,330 & 2,728 \\
\hline
\end{tabular}

Notes: * $P<0.05,{ }^{\text {*** }} P<0.01,{ }^{* * * * *} P<0.001$. HIV denotes human immunodeficiency virus; HHH denotes head of household; $\mathrm{Q}$ denotes quintile; na denotes not applicable. 
Table 4. Model results for viral load suppression after 24 months on ART: odds ratios and confidence intervals by sample

\begin{tabular}{|c|c|c|c|c|c|}
\hline Load suppression 24 months model variables & Pooled & Zambia & Malawi & Tanzania & Eswatin \\
\hline Gender: Male (Fem=1.0) & $0.219^{* *}$ & $0.287^{* *}$ & $0.239^{* *}$ & $0.154^{* *}$ & 0.969 \\
\hline & $(0.0680-0.704)$ & $(0.0893-0.924)$ & $(0.0730-0.784)$ & $(0.0356-0.663)$ & $(0.416-2.256)$ \\
\hline HIV+ Age: 25 to 49 years (Age 15-24=1) & 4.137 & $5.628^{* * *}$ & 1.586 & 0.940 & 1.560 \\
\hline & $(0.868-19.71)$ & $(1.789-17.70)$ & $(0.364-6.915)$ & $(0.356-2.478)$ & $(0.610-3.985)$ \\
\hline $50+$ years (Age $15-24=1)$ & 4.023 & $14.85^{* *}$ & 1.650 & 0.624 & $13.52^{* * *}$ \\
\hline & $(0.213-76.12)$ & $(1.346-164.0)$ & $(0.109-25.08)$ & $(0.0672-5.788)$ & $(5.158-35.44)$ \\
\hline \# Partners 12 months: One (None=1.0) & 0.954 & 0.841 & 0.827 & 0.435 & 0.483 \\
\hline & $(0.359-2.534)$ & $(0.229-3.088)$ & $(0.241-2.837)$ & $(0.0240-7.905)$ & $(0.131-1.777)$ \\
\hline Multiple (None=1.0) & $10.81^{* * *}$ & 5.147 & 0.817 & 0.319 & 0.669 \\
\hline & $(2.792-41.82)$ & $(0.219-121.0)$ & $(0.193-3.464)$ & $(0.0117-8.669)$ & $(0.114-3.938)$ \\
\hline Education: Secondary $(<S=1.0)$ & 2.270 & 1.298 & 0.521 & 0.934 & 0.745 \\
\hline & $(0.968-5.320)$ & $(0.588-2.865)$ & $(0.151-1.806)$ & $(0.0539-16.19)$ & $(0.345-1.607)$ \\
\hline Tertiary $(<S=1.0)$ & 1.194 & 3.267 & 1.471 & 1.069 & 0.647 \\
\hline & $(0.109-13.11)$ & $(0.355-30.04)$ & $(0.0762-28.38)$ & $(0.0436-26.24)$ & $(0.268-1.564)$ \\
\hline Wealth: Q 2-4 (W1=1.0) & 0.544 & 1.367 & 0.213 & 1.662 & 1.869 \\
\hline & $(0.0299-9.914)$ & $(0.307-6.101)$ & $(0.00344-13.17)$ & $(0.400-6.900)$ & $(0.888-3.934)$ \\
\hline Q5 (W1=1.0) & 0.504 & 2.546 & 0.282 & 0.457 & 3.154 \\
\hline & $(0.0327-7.775)$ & $(0.366-17.72)$ & $(0.00547-14.53)$ & $(0.106-1.958)$ & $(0.715-13.90)$ \\
\hline Travel time to care: $1-2$ hours $(<1$ hour $=1.0)$ & 0.985 & 1.182 & 0.846 & na & 0.819 \\
\hline & $(0.430-2.255)$ & $(0.413-3.386)$ & $(0.289-2.481)$ & & $(0.421-1.593)$ \\
\hline Over 2 hours $(<1$ hour $=1.0)$ & 1.453 & 1.287 & 0.882 & na & 0.763 \\
\hline & $(0.646-3.269)$ & $(0.388-4.264)$ & $(0.320-2.435)$ & & $(0.197-2.952)$ \\
\hline Household size: 4 to $9(1-3=1.0)$ & 0.891 & 0.595 & 1.286 & na & 1.169 \\
\hline & $(0.536-1.481)$ & $(0.158-2.248)$ & $(0.400-4.133)$ & & $(0.607-2.249)$ \\
\hline 10 and $\operatorname{Over}(1-3=1.0)$ & 0.507 & 0.289 & 1.482 & na & 2.387 \\
\hline & $(0.116-2.212)$ & $(0.0592-1.409)$ & $(0.221$ - 9.919) & & $(0.462-12.34)$ \\
\hline Household head: HIV + (HHH Neg =1.0) & $3.317^{* *}$ & 1.055 & 1.893 & $6.423^{* * *}$ & 0.785 \\
\hline & $(1.128-9.754)$ & $(0.304-3.670)$ & $(0.573-6.255)$ & $(1.752-23.55)$ & $(0.361-1.710)$ \\
\hline
\end{tabular}




\begin{tabular}{|c|c|c|c|c|c|}
\hline Household head: Male (HHH Fem=1.0) & 2.204 & 0.858 & $3.796^{* *}$ & 2.597 & 0.717 \\
\hline & $(0.663-7.331)$ & $(0.266-2.770)$ & $(1.121-12.85)$ & $(0.934-7.219)$ & $(0.345-1.493)$ \\
\hline \multirow[t]{2}{*}{ Work outside home Last 12 months (not $=1.0$ ) } & 0.621 & 0.539 & 0.942 & 2.343 & 0.812 \\
\hline & $(0.287-1.345)$ & $(0.206-1.410)$ & $(0.326-2.727)$ & $(0.554-9.918)$ & $(0.412-1.602)$ \\
\hline \multirow[t]{2}{*}{ HIV knowledge (low =1.0) } & 0.824 & na & na & na & na \\
\hline & $(0.355-1.913)$ & & & & \\
\hline \multirow[t]{2}{*}{ Stigma (unlikely=1.0) } & 1.186 & na & na & na & na \\
\hline & $(0.702-2.003)$ & & & & \\
\hline \multirow[t]{2}{*}{ Constant } & 1.633 & 3.000 & 14.28 & 5.048 & $11.72^{* * *}$ \\
\hline & $(0.0657-40.58)$ & $(0.224-40.24)$ & $(0.394-517.5)$ & $(0.0267-955.0)$ & $(2.306-59.59)$ \\
\hline Observations & 7,097 & 2,459 & 2,797 & 1,630 & 1,330 \\
\hline
\end{tabular}

Notes: ${ }^{*} P<0.05$, *** $P<0.01$, **** $P<0.001$. HIV denotes human immunodeficiency virus; HHH denotes head of household; $\mathrm{Q}$ denotes quintile; na denotes not applicable. 
Table 5. Gender data on outcomes: unadjusted and adjusted with pooled odds ratio models of awareness and VLS

\begin{tabular}{|c|c|c|c|}
\hline \multicolumn{4}{|c|}{ Descriptive data } \\
\hline & Women no Birth & $\begin{array}{r}\text { Women with } \\
\text { A birth }\end{array}$ & Men \\
\hline Awareness & $58.4 \%$ & $73.2 \%$ & $62.2 \%$ \\
\hline Viral load suppression & $51.4 \%$ & $64.3 \%$ & $52.4 \%$ \\
\hline VLS 24 months & $97.4 \%$ & $91.3 \%$ & $84.8 \%$ \\
\hline \multicolumn{4}{|c|}{ Logit regression model } \\
\hline & \multicolumn{3}{|c|}{ Gender dummy variables in the models } \\
\hline & $\begin{array}{r}\text { Women } \\
\text { (no birth=0), (birth=1) }\end{array}$ & $\begin{array}{r}\text { Men=0 } \\
\text { Women (birth=1) }\end{array}$ & $\begin{array}{r}\text { Men=0 } \\
\text { Women (no birth=1) }\end{array}$ \\
\hline \multirow[t]{2}{*}{ Awareness model } & $1.620^{* *}$ & $1.953^{* * *}$ & 1.221 \\
\hline & $(1.016-2.583)$ & $(1.535-2.486)$ & $(0.702-2.123)$ \\
\hline \multirow[t]{2}{*}{ Viral load suppression model } & 1.024 & $2.398^{* * *}$ & $2.098^{* *}$ \\
\hline & $(0.615-1.705)$ & $(1.852-3.105)$ & $(1.149-3.830)$ \\
\hline
\end{tabular}

Notes: $* P<0.05, * * P<0.01,{ }^{* * * *} P<0.001$. VLS24 denotes viral load was suppressed for all persons who started on antiretroviral therapy less than 24 months prior to the survey

We further examined the influence of the birthing experience on awareness and VLS by using logistic modeling. These models are reported in the bottom panel of Table $\underline{5}$. VLS 24 models are not included because of very small sample sizes and singularities in the models. For VLS and awareness we report three models for each: (1) a model for adult women who are HIV positive, including a variable that indicates if the woman had given birth or not; (2) a model including men with women who have not given birth; and (3) a model comparing men with women who have given birth. The models adjust for the same covariates included in Tables $\underline{2}, \underline{3}$ and $\underline{4}$. Significant covariates generally include age, HIV knowledge, education, wealth, and whether the head of household is HIV positive.

Awareness models show a large effect of birthing among women, but no difference between men and women who have not given birth. Women who have given birth have a $62 \%$ higher odds of awareness compared to other women. And women who have given birth have a 95\% higher chance of being aware than men, other things the same. This pattern indicates a large impact of the birthing experience on testing and awareness, and little or no gender difference in awareness otherwise.

For VLS the findings are different. There are no differences in VLS for women who have given birth relative to those who have not. Furthermore, women have higher VLS than men, whether they have given birth or not. So, the pattern for VLS suggests that birthing has no influence on the gender differential in VLS.

\section{DISCUSSION}

Table 6 summarizes the odds ratio findings for the various population segments we studied for which significant findings were seen in the pooled sample. The right column notes the importance of the various risk groups within the HIV-positive population in Zambia, Tanzania, Malawi and
Eswatini combined. These are the pertinent risk groups posing barriers for attaining the UNAIDS goals of effectively managing the HIV positive population.

\section{SUMMARY OF AWARENESS BARRIERS}

Results show that on average $68 \%$ of the HIV positive population is aware of their HIV status in our sample, well short of the 95\% goal for 2025. Some population attributes significantly contributing to low levels of awareness are also known risk factors for getting infected, including being young ( $<25$ years-old), having multiple partners, having low knowledge of HIV, and having a job outside the home (significant only in Tanzania). Additionally, individuals are less likely to know their HIV status if they are in the lowest wealth quintile, have an HIV-negative head of household, and are male. While men are $44 \%$ less likely to know they are HIV positive than comparable women, supplemental analysis demonstrated that birthing and exposure to PMTCT interventions have been effective in creating all or most of this differential. This means that PMTCT programs are doing a great job keeping awareness high for HIV-positive women but are not available for men.

\section{SUMMARY OF VLS BARRIERS}

Within the HIV-positive population, 59\% were found to have a suppressed viral load in the four study countries. This is well under the UNAIDS goal for 2025 of $86 \%$. Notably, HIV positive men are shown to be $48 \%$ less likely to be virally suppressed than women, all else equal. Persons who work outside of the home and those who have less than a secondary education are also less likely to show VLS, holding constant other factors. PMCTC programs and birthing -related access to services appears not to be a factor in explaining this gender differential.

Among new ART patients (ART initiated less than 24 months from time of survey), $89.5 \%$ on average continue 
Table 6. Summary of the HIV positive population segments with significant findings^

\begin{tabular}{|c|c|c|c|c|}
\hline $\begin{array}{l}\text { Risk Groups with } \\
\text { significant coefficients } \\
\text { in pooled models }\end{array}$ & $\begin{array}{l}\text { Awareness of HIV+ } \\
\text { persons }\end{array}$ & $\begin{array}{l}\text { Viral suppression of HIV } \\
\text { positive persons }\end{array}$ & $\begin{array}{l}\text { VLS of persons } \\
\text { starting ART }<24 \\
\text { months aago }\end{array}$ & $\begin{array}{l}\text { Share of HIV+ } \\
\text { persons in } \\
\text { study countries }\end{array}$ \\
\hline Men & $\begin{array}{l}44 \% \text { lower than } \\
\text { women* }\end{array}$ & $48 \%$ lower than Women & $\begin{array}{l}78 \% \text { lower than } \\
\text { Women }\end{array}$ & $36.2 \%$ \\
\hline Young adults 15-24 & $\begin{array}{l}\text { Only } 34 \% \text { as likely to } \\
\text { be aware }\end{array}$ & & Zambia & $10.7 \%$ \\
\hline Work outside home & $\begin{array}{l}\text { Tanzania } 34 \% \text { less } \\
\text { likely to be aware }\end{array}$ & $39 \%$ lower than others & & $2.6 \%$ \\
\hline $\begin{array}{l}\text { Having multiple } \\
\text { partners }\end{array}$ & $28 \%$ lower than others & Malawi & $\begin{array}{l}\text { Only } 10 \% \text { as } \\
\text { likely to be VLS }\end{array}$ & $15.2 \%$ \\
\hline $\begin{array}{l}\text { Less than secondary } \\
\text { education }\end{array}$ & & $\begin{array}{l}\text { About half as likely to be } \\
\text { VLS relative to those } \\
\text { with more educ }\end{array}$ & & $60.4 \%$ \\
\hline $\begin{array}{l}\text { Lowest quintile of } \\
\text { Wealth }\end{array}$ & $\begin{array}{l}\text { Only } 31 \% \text { as likely to } \\
\text { be aware as the rich } \\
\text { quintile }\end{array}$ & $\begin{array}{l}\text { Only } 69 \% \text { as likely to be } \\
\text { VLS than the rich quintile }\end{array}$ & & $14.9 \%$ \\
\hline $\begin{array}{l}\text { Household head is HIV } \\
\text { negative }\end{array}$ & $\begin{array}{l}\text { Only } 37 \% \text { as likely to } \\
\text { be aware than if HHH } \\
\text { is HIV+ }\end{array}$ & Tanzania & $\begin{array}{l}\text { Only } 30 \% \text { as } \\
\text { likely to be VLS }\end{array}$ & $20.0 \%$ \\
\hline $\begin{array}{l}\text { Having low HIV } \\
\text { knowledge }\end{array}$ & $\begin{array}{l}\text { Awareness is } 35 \% \\
\text { lower than those with } \\
\text { good knowledge }\end{array}$ & & & $27.6 \%$ \\
\hline
\end{tabular}

^ Only weighted pooled model odds ratios significant at $P<0.05$ are shown. If the pooled model is not significant, then significant country models are noted. Blank cells indicate no significant effects in pooled or country models. * Gender difference appears to result from greater awareness among women who have given birth, and positive impacts of testing as part of PMTCT programs. HIV+ denotes human immunodeficiency virus positive; ART<24 denotes antiretroviral treatment that was begun less than 24 months before taking the survey; VLS denotes viral load suppression.

to be virally suppressed. There is no explicit UNAIDS goal associated with this measure of VLS for new ART patients; however, it provides supplementary information about the short-term success of treatment programs in keeping patients enrolled and virally suppressed. In line with the other two goal-related measures, results show men newly on ART are $78 \%$ less likely to be VLS. New ART patients are also significantly more likely to show VLS if they have multiple partners, and if they live with a household head who is also HIV positive.

The results for awareness and VLS suppression both demonstrate a very large positive influence of higher age. This supports the finding that being a younger HIV positive adult presents a barrier to achieving UNAIDS goals because, other things the same, they have poorer patterns of testing and adherence to therapy. Why does higher age tend to increase medical compliance? Our data don't tell us much about this interesting question. And the literature does not offer more than several studies demonstrating that the elderly have better general compliance/adherence with medication, ${ }^{38}$ better adherence to HIV therapy, ${ }^{32-34}$ that better ART adherence among the elderly is associated with more education, more knowledge, and more trust in providers, ${ }^{39,40}$ and that the elderly face poorer HIV/AIDS outcomes due to poorer thymic function. ${ }^{41,45}$

High wealth is a significant factor (relative to the low wealth quintile) in the awareness models, the VLS pooled mode, and in the birthing analysis models (Table 2). This suggests that for both testing and adherence, the most wealthy segment of the population finds value in these health services beyond levels associated with comparable individuals who are poor. This may suggest the viability of private markets for testing and for ARVs.

The male population is the only significantly vulnerable population for all three of the metrics we studied for successfully managing HIV infection. As Camlin et al.(2016) ${ }^{6}$ noted, this is partially due to male belief in "by proxy" testing (the belief that the wife's HIV test results are synonymous to their own). Additionally, young men often feel healthy and have no reason to seek care early on. That study also reports successes in cleverly designed lottery programs which provide prizes for men who get tested. ${ }^{6}$

Women, particularly young women, have a high risk of being infected but are far more likely to be aware of positivity and more likely to remain virally suppressed than young men. This could also be because women have more touch points with the health care system during reproductive years. Awopegba et al. (2020) ${ }^{43}$ notes, however, that the implementation of opt out testing services for pregnant women differs from country to country. In their study of ANC HIV testing in 18 SSA countries, they found that HIV testing is only mandatory in Rwanda and Uganda and there is evidence that "a large portion of women who received ANC are not tested for HIV in some SSA countries." 43

We also found that good testing and ARV adherence behaviors appear to flow down to others within the same household. Heads of households who are HIV positive increase the likelihood that others in the household get tested (likelihood of awareness is much higher than for those living in a household without an HIV-positive household 
head) and VLS24 is also much higher.

\section{LIMITATIONS}

As any study based on household survey data, there are limitations of measures and sampling. In addition, there is a limitation concerning the availability of PHIA data. When this study began, of the 13 countries where PHIA surveys have been conducted, data was available for only four countries. PHIA data has since been released for four additional countries: Lesotho, Namibia, Uganda and Zimbabwe. There are also potentially important behavior factors that are not available from PHIA data, including prior relationship with care providers and whether ARV refill of drugs is available in the community of residence or not.

\section{CONCLUSIONS}

Factors that may pose barriers to awareness or VLS include being young, having multiple partners, having a job outside the home, low education, low wealth levels, low knowledge of HIV, and the HIV status and gender of the household head. For both awareness and VLS, gender differences pose the most consistent barrier: women's rates of being aware and virally suppressed are almost twice as high as for comparable men. The awareness gender differential seems primarily due to the testing and other services provided during antenatal care for women who have been pregnant and give birth. But the VLS gender gap is not due to birthing-related services. New programs to routinely integrate HIV testing into men's activities and health care in workplaces or other settings might improve men's awareness and compliance with treatment. Also needed are more effective efforts to target sectors of the population that are less likely to adhere to treatment regimens, such as persons with low education levels and poor HIV knowledge.

\section{FUNDING}

This paper was produced with funding from Centers for Disease Control and Prevention (CDC), Division of Global HIV/ AIDS and TB (DGHT) under Cooperative Agreement Number U2GGH001531. Its contents are solely the responsibility of Cardno and Brandeis University and do not necessarily represent the official views of CDC.

\section{AUTHORSHIP CONTRIBUTIONS}

Author contributions to the manuscript were: study funding: AKN; study design GG, RSK and ED; computing and weighting EBO; literature review GG, JB; and writing GG and CLH.

\section{COMPETING INTERESTS}

The authors have completed the Unified Competing Interest form at www.icmje.org and declare no conflicts of interest.

\section{CORRESPONDENCE TO:}

\section{Gary Gaumer, PhD.}

Institute for Global Health and Development, The Heller School for Social Policy and Management, Brandeis University, 415 South Street MS035, Waltham, Massachusetts, USA 02453.

\section{garygaumer@gmail.com}

Submitted: May 18, 2021 GMT, Accepted: July 28, 2021 GMT 


\section{REFERENCES}

1. UNAIDS. Knowledge Is Power-Know Your Status, Know Your Viral Load. UNAIDS; 2018. Accessed May 7, 2021. https://www.unaids.org/en/resources/documen ts/2018/knowledge-is-power-report

2. Asaolu IO, Gunn JK, Center KE, Koss MP, Iwelunmor JI, Ehiri JE. Predictors of HIV testing among youth in sub-Saharan Africa: A cross-sectional study. PLoS One. 2016;11(10):e0164052. doi:10.1371/i ournal.pone.0164052

3. Camlin CS, Koss CA, Getahun M, et al. Understanding demand for PrEP and early experiences of PrEP use among young adults in rural Kenya and Uganda: A qualitative study. AIDS Behav. 2020;24(7):2149-2162. doi:10.1007/s10461-020-0278 $\underline{0-\mathrm{X}}$

4. Sharma M, Ying R, Tarr G, Barnabas R. Systematic review and meta-analysis of community and facilitybased HIV testing to address linkage to care gaps in sub-Saharan Africa. Nature. 2015;528(7580):S77-S85. doi:10.1038/nature16044

5. Teklehaimanot HD, Teklehaimanot A, Yohannes M, Biratu D. Factors influencing the uptake of voluntary HIV counseling and testing in rural Ethiopia: A cross sectional study. BMC Public Health. 2016;16(241). do $\mathrm{i}: 10.1186 / \mathrm{s} 12889-016-2918-\mathrm{z}$

6. Camlin CS, Ssemmondo E, Chamie G, et al. Men "missing" from population-based HIV testing: Insights from qualitative research. AIDS Care. 2016;28(sup3):67-73. doi:10.1080/09540121.2016.116 $\underline{4806}$

7. Holmes KK, Bertozzi S, Bloom BR, Jha P, eds. Disease Control Priorities, Third Edition (Volume 6): Major Infectious Diseases. The World Bank; 2017. doi:1 0.1596/978-1-4648-0524-0

8. Cohen MS, Chen YQ, McCauley M, et al. Prevention of HIV-1 infection with early antiretroviral therapy. $N$ Engl J Med. 2011;365(6):493-505. doi:10.1056/NEJMoa $\underline{1105243}$

9. Cohen MS, Chen YQ, McCauley M, et al. Antiretroviral therapy for the prevention of HIV-1 transmission. N Engl J Med. 2016;375(9):830-839. do i:10.1056/NEJMoa1600693

10. Cohen MS, Dye C, Fraser C, Miller WC, Powers KA, Williams BG. HIV treatment as prevention: debate and commentary-Will early infection compromise treatment-as-prevention strategies? PLoS Med. 2012;9(7):e1001232. doi:10.1371/journal.pmed.10012 $\underline{32}$
11. Cohen RL, Li Y, Giese R, Mancuso JD. An evaluation of the President's Emergency Plan for AIDS Relief Effect on health systems strengthening in sub-Saharan Africa. J Acquir Immune Defic Syndr. 2013;62(4):471-479. doi:10.1097/OAI.0b013e3182816 $\underline{\mathrm{a} 86}$

12. Delva W, Wilson DP, Abu-Raddad L, et al. HIV Treatment as prevention: Principles of good HIV epidemiology modelling for public health decisionmaking in all modes of prevention and evaluation. PLoS Med. 2012;9(7):e1001239. doi:10.1371/journal.p med.1001239

13. The TEMPRANO ANRS 12136 Study Group. A trial of early antiretrovirals and isoniazid preventive therapy in Africa. N Engl J Med. 2015;373(9):808-822. doi:10.1056/NEJMoa1507198

14. Eaton EF, Saag MS, Mugavero M. Engagement in human immunodeficiency virus care. Infect Dis Clin North Am. 2014;29(3):355-369. doi:10.1016/j.idc.201 4.06.004

15. Suraratdecha C, Stuart RM, Manopaiboon C, et al. Cost and cost - effectiveness analysis of pre - exposure prophylaxis among men who have sex with men in two hospitals in Thailand. J Int AIDS Soc. 2018;21(S5). doi:10.1002/jia2.25129

16. Rodger AJ, Cambiano V, Bruun T, et al. Sexual activity without condoms and risk of HIV transmission in serodifferent couples when the HIVpositive partner is using suppressive antiretroviral therapy. JAMA. 2016;316(2):171-181. doi:10.1001/jam a. 2016.5148

17. Rosen S, Fox MP, Gill CJ. Patient retention in antiretroviral therapy programs in sub-Saharan Africa: A systematic review. PLoS Med. 2007;4(10):e298. doi:10.1371/journal.pmed.0040298

18. Chi BH, Yiannoutsos CT, Westfall AO, et al. Universal definition of loss to follow-up in HIV treatment programs: A statistical analysis of 111 facilities in Africa, Asia, and Latin America. PLoS Med. 2011;8(10):e1001111. doi:10.1371/journal.pme d.1001111

19. Fox MP, Rosen S. Patient retention in antiretroviral therapy programs up to three years on treatment in sub-Saharan Africa, 2007-2009: Systematic review: Patient retention in antiretroviral therapy programs. Trop Med Int Health. 2010;15:1-15 doi:10.1111/j.1365-3156.2010.02508.x 
20. WHO, UNICEF, UNAIDS. Global Update on HIV Treatment 2013: Results, Impact and Opportunities. WHO; 2013. Accessed April 1, 2021. https://www.wh o.int/hiv/pub/progressreports/update2013/en/

21. Wekesa P, McLigeyo A, Owuor K, Mwangi J, Nganga E, Masamaro K. Factors associated with 36-month loss to follow-up and mortality outcomes among HIV-infected adults on antiretroviral therapy in Central Kenya. BMC Public Health. 2020;20(1):328. doi:10.1186/s12889-020-8426-1

22. Berheto T, Haile D, Mohammed S. Predictors of loss to follow-up in patients living with HIV/AIDS after initiation of antiretroviral therapy. $N$ Am J Med Sci. 2014;6(9):453-459.

23. Aliyu A, El-Kamary S, Brown J, et al. Performance and trend for quality of service in a large HIV/AIDS treatment program in Nigeria. AIDS Res Ther. 2019;16(1):29. doi:10.1186/s12981-019-0242-2

24. Vella V, Govender T, Dlamini S, et al. Retrospective study on the critical factors for retaining patients on antiretroviral therapy in KwaZulu-Natal, South Africa. J Acquir Immune Defic Syndr. 2010;55(1):109-116. doi:10.1097/OAI.0b013e31 $\underline{81 \mathrm{e} 7744 \mathrm{e}}$

25. Hassan AS, Mwaringa SM, Ndirangu KK, Sanders EJ, De Wit TFR, Berkley JA. Incidence and predictors of attrition from antiretroviral care among adults in a rural HIV clinic in coastal Kenya: a retrospective cohort study. BMC Public Health. 2015;15(1):1-9.

26. Karcher H, Omondi A, Odera J, Kunz A, Harms G. Risk factors for treatment denial and loss to follow-up in an antiretroviral treatment cohort in Kenya. Trop Med Int Health. 2007;12(5):687-694.

27. MacKinnon DP, Krull JL, Lockwood CM. Mediation, confounding and suppression. Prev Sci. 2000;1(4):173.

28. Mutasa - Apollo T, Ford N, Wiens M, et al. Effect of frequency of clinic visits and medication pick - up on antiretroviral treatment outcomes: a systematic literature review and meta - analysis. J Int AIDS Soc. 2017;20(suppl 4):21647.

29. Mutasa - Apollo T, Shiraishi RW, Takarinda KC, Dzangare J, Mugurungi O, Murungu J. Patient retention, clinical outcomes and attrition-associated factors of HIV-infected patients enrolled in Zimbabwe's National Antiretroviral Therapy Programme, 2007-2010. PLoS One. 2014;9(1):e86305.

30. Sabapathy K, Ford N, Nyein Chan K, et al. Treatment outcomes from the largest antiretroviral treatment program in Myanmar (Burma). J Acquir Immune Defic Syndr. 2012;60(2):e53-62.
31. Ugoji C, Okere N, Dakum P, et al. Correlates of patient retention in HIV care and treatment programs in Nigeria. Curr HIV Res. 2015;13(4):300-307.

32. Ghidei L, Simone MJ, Salow MJ, et al. Aging, antiretrovirals, and adherence: a meta analysis of adherence among older HIV-infected individuals. Drugs \& Aging. 2013;30(10):809-819.

33. Knight L, Mukumbang FC, Schatz E. Behavioral and cognitive interventions to improve treatment adherence and access to HIV care among older adults in sub-Saharan Africa: An updated systematic review. Syst Rev. 2018;7:114. doi:10.1186/s13643-018-0759-9

34. Kunutsor S, Walley J, Muchuro S, et al. Improving adherence to antiretroviral therapy in sub-Saharan African HIV-positive populations: an enhanced adherence package. AIDS Care.

2012;24(10):1308-1315. doi:10.1080/09540121.2012.6 $\underline{61833}$

35. Tomita A, Vandormael A, Bärnighausen T, et al. Sociobehavioral and community predictors of unsuppressed HIV viral load: Multilevel results from a hyperendemic rural South African population. AIDS. 2019;33(3):559-569. doi:10.1097/OAD.000000000000 $\underline{2100}$

36. Peltzer K, Pengpid S. Socioeconomic factors in adherence to HIV therapy in low- and middle-income countries. J Health Popul Nutr. 2013;31(2):150-170. do i:10.3329/jhpn.v31i2.16379

37. Sahay S, Dhayarkar S, Reddy K. Optimizing adherence to antiretroviral therapy. Indian J Med Res. 2011;134(6):835. doi:10.4103/0971-5916.92629

38. Fedder DO. Drug use in the elderly: issues of noncompliance. Drug Intell Clin Pharm. 1984;18(2):158-162. doi:10.1177/10600280840180021 9

39. Jin H, Kim Y, Rhie SJ. Factors affecting medication adherence in elderly people. Patient Prefer Adherence. 2016;10:2117-2125.

40. Mehta S, Moore R, Graham NMH. Potential factors affecting adherence with HIV therapy. AIDS. 1997;11(14):1665-1670.

41. Nguyen N, Holodniy M. HIV infection in the elderly. Clin Interv Aging. 2008;3(3):453-472.

42. ICAP Global Health. PHIA Project PopulationBased HIV Population Assessment: Guiding the Global HIV Response. Accessed April 20, 2021. https://phia-d ata.icap.columbia.edu/files 
43. Awopegba OE, Kalu A, Ahinkorah BO, Seidu AA, Ajayi AI. Prenatal care coverage and correlates of HIV testing in sub-Saharan Africa: Insight from demographic and health surveys of 16 countries. PLoS One. 2020;15(11):e0242001. doi:10.1371/journal.pon e.0242001
44. Mnyani CN, Tait CL, Peters RPH, et al. Implementation of a PMTCT programme in a high HIV prevalence setting in Johannesburg, South Africa: 2002-2015. South Afr J HIV Med. 2020;21(1). $\underline{\mathrm{d}}$ oi:10.4102/sajhivmed.v21i1.1024

45. Zelenetz P, Epstein M. HIV in the Elderly. AIDS Patient Care and STDs. Published online 2009. doi:1 0.1089/apc.1998.12.255 


\section{SUPPLEMENTARY MATERIALS}

\section{Online Supplementary Document}

Download: https://www.joghr.org/article/28068-household-factors-associated-with-managing-the-hiv-positivepopulation-and-meeting-the-unaids-goals/attachment/70298.docx 